\title{
Theoretical foundations for e-learning environments direct to Virtual Scientific Experiments
}

\author{
Centre of Excellence "Metodi e sistemi per l'Apprendimento e la Conoscenza" Research Group \\ University of Salerno
}

\begin{abstract}
In this work we want to put in evidence the necessity to integrate theoretical, methodological and didactical aspects with innovative e-learning systems, in order to hypothesize possible learning models able to facilitate and qualify the e-learning world. Specifically, our aim will be direct to theoretical learning models for Virtual Scientific Experiments to be implemented inside the platforms. Therefore, the result to be achieved comes from the interaction of two different "macro-environments": the pedagogical-didactical world and the informatics world. The first one puts in evidence the methodological aspects and the fundamental importance of the didactical transposition ${ }^{1}$ (Chevallard, 1985, 1994; Cornu, Vergnioux, 1992) in order to structure in the best way the experiments foreseen by experts of the discipline. The second one, instead, will have the task of structuring and realizing the suitable virtual learning environments and the various phases of single experiments, taking into account the methodological indications arisen by the pedagogical world. Thus in the next future, our aim will be based on these considerations to obtain motivating Virtual Scientific Experiments effectively usable by the learner, allowing the dissemination of scientific knowledge through the Internet.
\end{abstract}

Keywords: Didactics, Methodology, Constructivist learning, Collaborative learning, Active learning, Socio-Cultural approach, Situation approach, Models, Virtual Scientific Experiments, A-didactical Situations.

\section{INTRODUCTION}

When one talks about e-learning environments usually refers to organized contexts where the attention is particularly direct to the contents and the teaching way, giving often very little attention to the pupil and his effective learning. The idea, more or less explicit, seems to be the following: a better teaching automatically determines a better learning, but nowadays the didactics agrees with the fact that this concept is not at all true and cannot be taken for granted. Pleasant and motivating learning environments, but not critically thought from the methodological and didactic point of view, do not assure necessarily the knowledge acquisition by the learner.

We have to create such environments which consider the varied pedagogical and didactical results obtained in these years, apt to promote the learning and to realise those conditions essential to the learner's knowledge acquisition. We believe it necessary to accomplish the fusion of the two worlds: the pedagogic-didactic and the informatics ones. For this reason, our attempt is focused to the study of learning environments, aiming at the effective, personal and real construction of knowledge by the learner. In line with the Laneve's thought (1998) we think that the teacher, in this case the author of the platform, does not determine the learning (which is a pupil's prerogative), but only produces the «pupilling», that is the capacities and the means to make him potentially able to learn inside his institution.

\footnotetext{
${ }^{1}$ The didactical transposition has to be seen as the transformation work of knowledge into teaching object, which depends on the place, the audience and the specific didactic aims of the particular context. In an e-learning environment, the author will have to make a transposition from knowledge (which rises from the research) to teaching knowledge (which is decided by the institutions) to taught knowledge (which the author chooses as object specific of his didactic learning environment). The passage from knowledge to teaching knowledge, is filtered by the author's epistemological choices, which depend on the convictions, on his/her "implicit philosophies", on his/her idea about the didactical transposition, on the influence of noosphere ("the outside cloak containing all the people who in the society think to the contents and the methods of teaching», Godino, 1993).
} 
The same concept is again found in other authors, among them Papert (1990), who says: "A better learning does not happen because the teacher finds better teaching methods, but it happens when we give to the learner better opportunities to build», but these opportunities may be studied and structured only referring to the real pedagogic and didactic demands requested by the pupil. In particular, we will proceed by individualising among the theoretical aspects, which are the useful elements to build learning environments direct to the realization of effective Virtual Scientific Experiments.

\section{THEORETICAL FOUNDATIONS UNDERLYING POSSIBLE LEARNING MODELS}

We think that the choices of educational tools and methodologies represent important elements in a didactic programming process, that need of an a priori reflection, in order to assume and to structure possible and useful theoretical models for the various e-learning requirements.

Precisely, we will draw from the theory, those aspects which in our opinion become necessary for the realization of effective learning models for the Virtual Scientific Experiments. The theoretical aspects we need to identify in this field are based on the constructivist learning theory, with a socio-cultural and situational approach (Jonassen, 1994, 1995; Brown, Campione, 1994, Brown 1997; Wenger, 1998; Varisco, 2002).

When we hypothesize such models, we consider in general that the knowing must be:

- $\quad$ the product of the pupil's active building;

- $\quad$ "situated", that is reported to a precise social and cultural context, but always staying in relation to other contexts;

- $\quad$ the result of particular forms of cooperation and social negotiation;

- $\quad$ used and redefined in other cultural and social contexts (Jonassen, 1994).

In this vision, which sees as fundamental for an effective learning, such elements as the building, the context and the cooperation, we define the principal features of an environment suitable for Virtual Scientific Experiments, that may be named social-constructivist. Therefore our assumed models point particular attention to the learning, keeping as reference the current didactic paradigms.

In this scenario, the learning, in line with the Jonassen's thought (1995), is seen as:

- active, namely aware and responsible, based on the personal learner's construction: "... it is very important that the students have experiences that allow them to take "care of their own learning"》 (Wenger, 1998; Brousseau 1986);

- collaborative, since who works in a community, learns and builds his knowledge through scaffolding (support) offered by every actor of the community (Brousseau 1986);

- intentional, since it involves actively and fully the learner in the pursuit of general cognitive, aware and shared aims which the strategic role of meta-cognition is associated to, that is the subject's consciousness and comprehension of his own cognitive processes;

- situated, as the learning tasks coincide with tasks meaningful of the real world, these latter being simulated through learning environments based on real cases or problems;

- $\quad$ reflexive, because the students organize what they learn by thinking on the developed processes and the decisions taken.

As D'Amore (1999) reports: "The realization of this constructive climate takes place when the learner is placed in the condition to be able to interact with the environment to organize his own learning» and we want to offer the student just this possibility.

Considering this approach, our task is to define the principal features of specific e-learning environments, which underline the active and strategic nature of the learning, besides, to the consideration of a collaborative approach: the learning is the result of social learning instances, in line with the notion of "community of students who learn" supported by Brown, Campione (1994) and Brown (1997). In this theory, the learning assumes a meaning in a social environment, where several people think, act and think together: the "practice community". In the "practice community" various people are reciprocally involved in a meaning experience concerning the building of the learning, stimulating and choosing with a strong sense of responsibility the initiatives which are defined through the continuous negotiation. For this reason, it is important to foreseeing in the e-learning environments some tools for the communication (synchronous as text, chat, audio-video tools, graphics, shared blackboard, file transfer), realizing in this way the so-called Live Session or Virtual Classes; asynchronous as electronic mail, videoconferences, loud messages, fax, Bulletin Board, thematic messaging system and thematic forum); systems for the resources sharing (synchronous as shared screen, electronic blackboard, tools for the projects representation; 
asynchronous as access to the data flow or data base); systems to support the group processes (project management, shared calendars, vote tools, tools for the generation of ideas and free discussions).

Our educational and didactic purposes do not refer only to the acquisition of knowledge, skills and competences but aim at the "use of knowledge" by each student. The use of knowledge has to be practiced by the learner in the original context, interacting with his/her community and also in other contexts and communities. The student has not simply to learn but also to manage his/her own knowledge, being in this way able to choice among several complex information the most important one and to resolve problematic events.

In the light of these considerations, we think that the learning model suitable to the Virtual Scientific Experiments can be based on the "Situations Theory" of Brousseau (1986). This theory is a "weak" learning constructivist theory, which considers that the learning has to be produced in an active way through the learner's personal construction and through the resolution problems. In this theory, Brousseau distinguishes between didactical situations, adidactical and notdidactical ones, the same are better explained by D'Amore (1999). For our purpose we think it sufficient to emphasize the difference between didactical and adidactical situation.

In a didactical situation, the teacher shows the specific didactic objective at the beginning, so that both teacher and learner know which is the didactic objective and the cognitive goal to achieve. The situation is all explicit, structured with definite "game rules" which are known by the learner. But, as said by Brousseau, in this situation we cannot be sure that there is a real and genuine learning by the students, because they only use the learning strategies to demonstrate to the teacher that they have learned, but in this way they do not take care of realising an effective knowledge acquisition.

On the contrary, in an adidactical situation, the didactic objective is known only by the teacher and not by the learner. The teacher inputs are not explicitly didactic, that is the learners are involved in stimulating activities but they do not know the foreseen specific learning objectives. This situation occurs when in the organised learning environment the didactic intention is not declared. Brousseau tells of devolution, that is the teacher entrusts the learning responsibility to each student, stimulating him/her to take personally care of his own knowledge construction. In such situation, the learner achieves his/her knowledge through personal implication, while the teacher accomplishes a delicate rule to delegate, prepare and support the learner activities: "The teacher without pride, has to help the student in order to eliminate more possible the didactic artifices from the situation, and to allow him/her to have a personal and objective knowledge» (Brousseau, 1986). In the adidactical situation the teacher officially institutionalises the knowledge only after the students have achieved their didactic objective, that is the teacher recognises the acquired students' knowledge through their personal care, like knowledge usable and suitable to the school context.

Between the situations highlighted by Brousseau, we are assuming for the Virtual Scientific Experiments some theoretical learning models referred to the adidactical situations. In fact, we consider very important to explicit to the learner, since the beginning, the motivation of the experiment, in order to satisfy the intentional aspect of the learning pointed out by Jonnasen (1995), but subsequently we will put the student in adidactical situations through stimulating simulations where the didactic intention is not explicit. In this active learning phase, in which the student actually constructs his/her knowledge, it is fundamental that he/she has at disposal the greatest variety of possible resources, provided that only through a comparison between them he/she will be able to construct personally and effectively his/her own knowledge.

We often witness the realization of organized learning environments for specific subjects, where activities are proposed without declaring the specific purpose. The user well knows that the activity will have the purpose to allow him/her to construct knowledge, but in this case he/she does not explicitly know what it will be. If he/she decides to take part in the activity, that is if accepts to involve himself/herself, then he/she sets himself/herself free from the "contractual" conditionings and takes part in adidactical activity.

The author initially dissimulates his/her didactic purpose and his/her will to teach, in order to make the learner responsible of the improvement of his/her cognitive situation and to let him construct his own knowledge. This happens by realizing up situations that encourage devolution and subsequent implication.

After this phase, the personal knowledge constructed by each single student, can be accepted by all interested community through the validation ${ }^{2}$ and socialization phases, which are included in the vision of collaborative

${ }^{2}$ The validation is the process adopted and followed to reach the conviction that a certain obtained result (or a constructed idea) answers explicitly to the requests. The validation occurs when a student proposes his/her own conceptual construction to others, putting himself in a explicitly communicative situation, orienting his attention to 
learning. In the end, this knowledge will be made official by the knowledge institutionalisation phase foreseen by the author.

Below, we report the interpretation summarised by Martini (2000), showing the implicit interactive dynamics according to Brouseseau (1986), so to simplify the difference between didactical and adidactical situation.

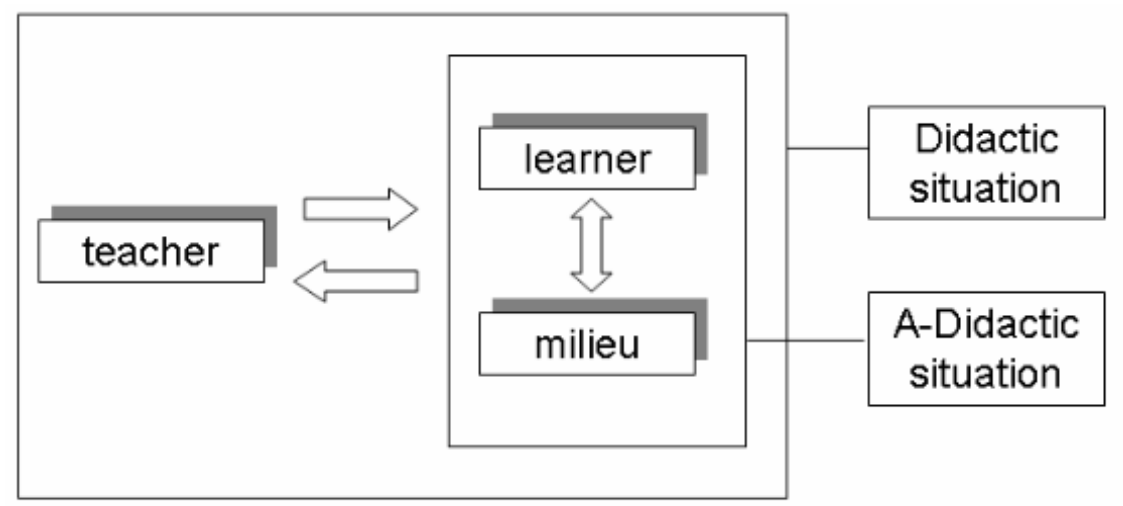

FIGURE1: let us observe that the adidactical situation only refers to learner and milieu, on the contrary, the didactical situation refers also to teacher.

In the adidactical situations the relationship author-learner is interrupted on behalf of the relationship learnersituation: the learner produces his/her knowledge as personal answer to the requests of milieu instead of the author's expectations. In the Brousseau's Theory of the Situations, he formally translates the activities connected to the adidactical situations in interaction between learner and milieu. This interaction works as an "antagonist system" for the learner, while the author encourages the adaptations using an appropriate choice of the situation to introduce to the learner. Therefore, learners and knowledge object are involved in the adidactical situation, but not the author: the situation suggests some demands and the students answer to these. The learner makes some attempts (alone or in group), he/she verifies that the attempts fail or are effective, then reproduces several times the test, modifies his/her knowledge system because of the adaptations occuring in using various strategies. So the demand to execute this represents a need motivated by the same situation and not by the author: if the student is not able to explain the experiment immediately, he discusses with the other students in order to reach an agreement on the explanation (for this reason we foresee the collaborative learning phase), so the knowledge is produced even if it has not been explicitly requested by the author. In conclusion, when the learner will reach the cognitive aim foreseen by the situation, the author will present the institutionalisation of the knowledge phase, where the "personal knowledge" becomes "institutional knowledge". These adidactical situations seem to be the most suitable to the knowledge construction and for this reason we consider them also as the most suitable to be used in the Virtual Scientific Experiments learning.

Now we want to summarise in a personal way some of the above mentioned concepts with regard to the Theory of the Situations of Brousseau, useful, in our opinion, to be transferred in e-learning environments direct to the Virtual Scientific Experiments through the following scheme:

the transformation of his private personal knowledge into a communication product, therefore validating his/her own construction.

${ }^{3}$ In the ambit of the Theory of the Situations, Brousseau (1989, p. 312) introduces the notion of means or environment (in French: milieu), also in order to outline the systemic character of his approach, very significant for our purposes since it represents the subsystem with which the student directly interacts (materials, virtual games, simulations, etc.). This milieu, at the beginning is defined as the set of all things act on the student or the pupil acts on. It serves to define, inside the didactic system, the part related to specific a-didactic uses, arranged by the author in order to achieve the didactic objectives, but without the necessary and constant presence of such aims (for example without the direct participation of the author). 


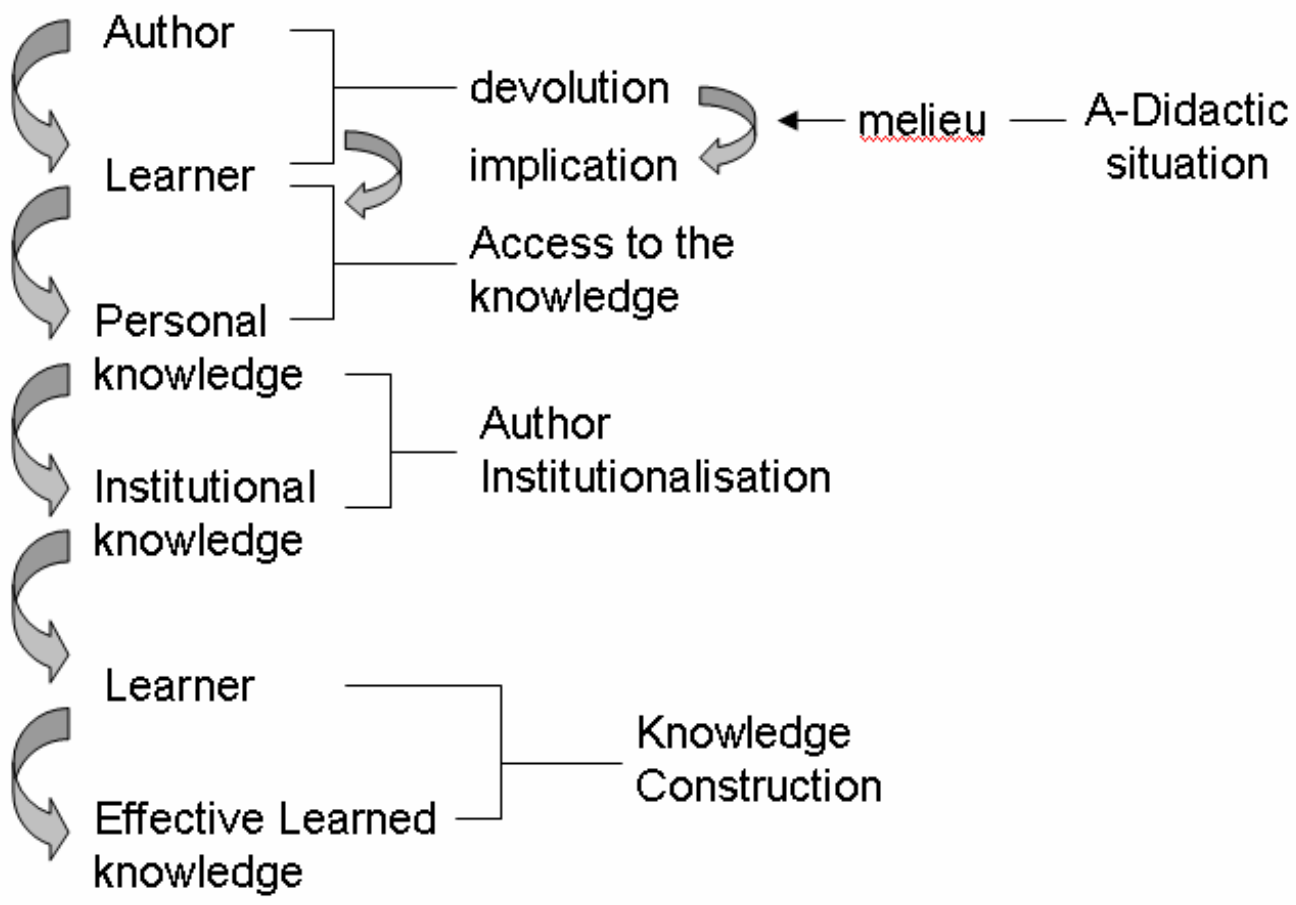

FIGURE 2: The author makes the learners responsible for the learning through adidactical situations mediated by the milieu, allowing the implication of the student who accesses to a "personal knowledge" which is afterwards institutionalised by the author and becomes "institutional knowledge". This "institutional knowledge" reaches the student allowing the knowledge construction and translating itself into "effective learned knowledge".

\section{FUTURE WORK}

Our future intents are included in the following points:

- to study in depth the relations between pedagogic-didactic aspects and e-learning environments;

- to identify, among the above mentioned theoretical aspects, the learning models useful for several contexts, in particular for the realization of effective Virtual Scientific Experiments;

- to structure some stimulating learning environments, starting from the previous points, and in particular, to realize varied Virtual Scientific Experiments effectively usable by the students. For their realization it will be necessary to foresee and arrange appropriate technological infrastructures, which fulfil the learning demands.

\section{BIBLIOGRAFIA}

[1] Brousseau G. (1986). Fondements et méthodes de la didactique des mathématiques. Recherches en didactique des mathématiques. 7, 2, 33-115.

[2] Brousseau G. (1989). Le contrat didactique: le milieu. Recherches en didactique de mathématiques. 9, 3, 309336.

[3] Brown A. L., Campione C. (1994). Guided Discovery in a Community of Learners. In: K. McGilly (a cura di). Classroom Lesson: Integrating Cognitive Theory and Classroom Pratice. MIT Press. Cambridge (MA). 227-270.

[4] Brown A. L. (1997). Transforming Scholls Into Communities of Thinking and Learning About Serrious Matters. American Psychologist. 52, 4, 399-413.

[5] Chevallard Y. (1985). La transposition didactique. Du savoir savant au savoir enseigné. Grenoble: La Pensée Sauvage.

[6] Chevallard Y. (1994). Les processus de transposition didactique et leur théorisation. In: Arsac G., Chevallard Y., Martinand J. L., Tiberghien A. (eds.) (1994). 135-180.

[7] Cornu L., Vergnioux A. (1992). La didactique en questions. Paris: Hachette.

[8] D'Amore B. (1999). Elementi di Didattica della Matematica. Bologna: Pitagora.

[9] Godino J. D. (1993). La metafora ecologica en el estudio de la noosfera matematica. Quadrante. 2, 1, 9-22.

[10] Jonassen D.H. (1994). Thinking Tecnology. Educational Technology. 34-4, 34-37.

[11] Jonassen D.H. (1995). Supporting Communities of Learning with Technology: A Vision for Integrating Technology with Learning in Schools. Educational Technology. 35-4, 60-63.

[12] Laneve C. (1998). Elementi di Didattica generale. Brescia: La Scuola. 
[13] Papert S. (1990). Introduction. Constructionist learning. Boston, MA: MIT Media Laboratory. pp. 1-8.

[14] Varisco B. M. (2002). Costruttivismo socio-culturale. Roma: Carrocci.

[15] Wenger E. (1998). Communities of Practice. Learning, Meaning, and Identity, Cambridge (UK). Cambridge University Press. 